\title{
Erste Person Singular
}

Korrespondenz:

Dr. med. Bernhard Gurtner

Eggstrasse 76

CH-8620 Wetzikon

\section{Bernhard Gurtner}

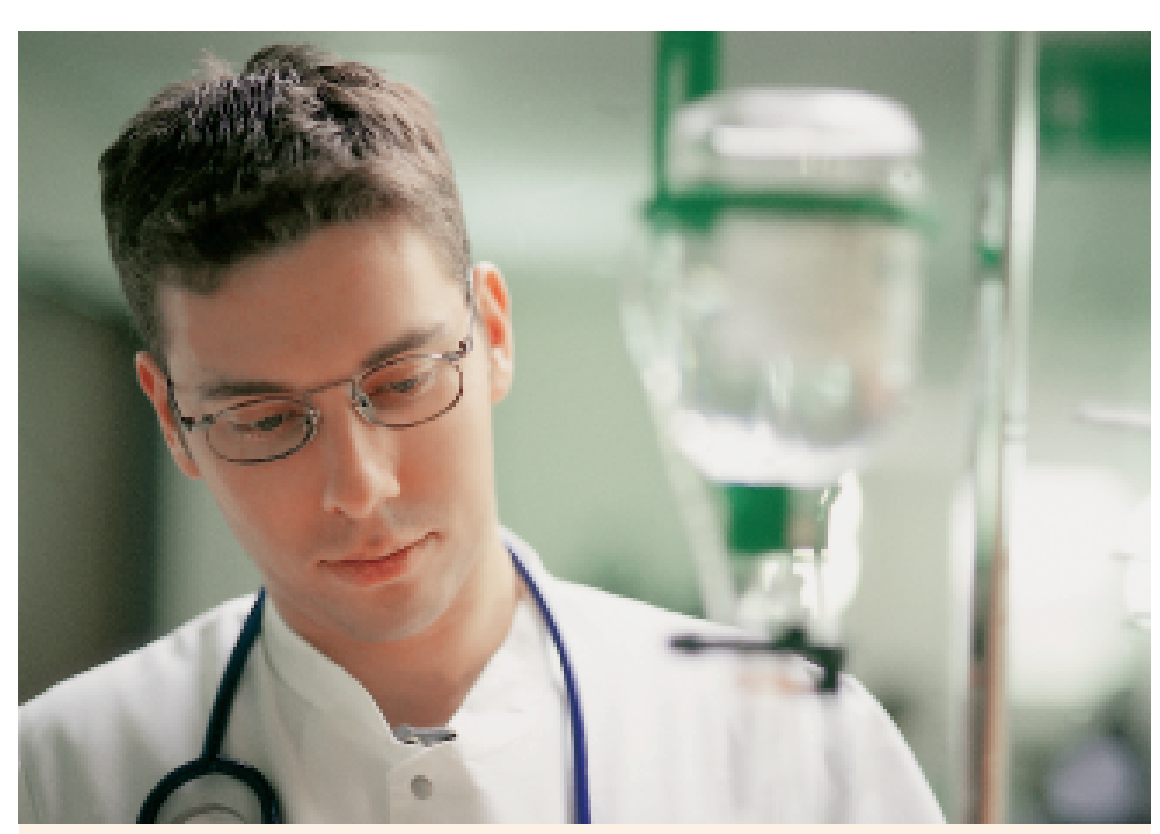

Ich, ich, ich oder das Manhattan-Syndrom.

«Ich mache notfallmässig ein MRI», antwortete der Kandidat im chirurgischen Staatsexamen auf die Frage, was unverzüglich zu tun sei, wenn sich eine Frau beim Gemüserüsten so in den Zeigefinger geschnitten hat, dass das Blut an die Küchendecke spritzt [1].

Wäre der geprüfte Medizinstudent bei den Pfadfindern gewesen oder hätte er die bahrenschleppende Ausbildung bei den Schweizer Sanitätstruppen genossen, könnte seine Antwort
«Ich binde sofort ab zwischen Wunde und Herz» gelautet haben, was bekanntlich zu Problemen führt, wenn jemand heftig aus der Schläfenarterie blutet. Die ebenso atemraubende Absicht, nach einem Schnitt in den Finger notfallmässig ein MRI anzufertigen, beweist nicht nur, wie realitätsfern ein Studium durchlaufen werden kann, sondern sie zeigt auch, wie prompt der junge Mediziner im Spitalpraktikum den klinischen Slang übernommen hat: «Ich mache ein MRI, ich mache ein weisses Blutbild, ich habe einen 〈Thorax〉 gemacht ...»

«... machen lassen!» unterbrach uns ein Chefarzt jedesmal mit schneidender Stimme, wenn wir uns am Rapport damit brüsteten, was wir alles gemacht hatten. Gewiss, wir hatten nur bunte Auftragszettel für Dienstlaborantinnen und Röntgenassistentinnen ausgefüllt und in der Nacht einige Untersuchungen zuviel angekreuzt, um auf der Morgenvisite nicht in den Hammer «Warum haben Sie nicht?» zu laufen. «Ich hätte noch eine Amylase gemacht», bemerkte dann der kritische Boss und wir murmelten mit verbissenen Zähnen «... machen lassen!».

Nun gut, aus dem Geschichtsunterricht wissen wir, dass Cheops die Pyramide erbaut und Napoleon die Schlacht bei Austerlitz gewonnen hat - eigenhändig? Sie erwarben sich Ruhm, weil viele andere geschuftet und gelitten haben. Und so wird eben auch im ärztlichen Alltag oft die erste Person im Singular vorgeschoben, wenn andere im Hintergrund gewirkt haben: «Ich habe ein CT gemacht.»

Geht aber etwas schief, hat man den Patienten zu früh von der IPS auf die Station verlegt, hat man eine Antikoagulation bewusst unterlassen oder ehrlicher gesagt vergessen. Niemand weiss und notiert, wer es getan oder entschieden hat; man hat, man hat ihn - Manhattan-Syndrom habe ich diese sprachliche Verwischung der Verantwortlichkeit einmal genannt.

«Wir fanden bei dem Patienten mit atypischen Kniebeschwerden eine Bakerzyste», heisst es hingegen stolz im Austrittsbericht der grossen Klinik, obwohl schon im Einweisungszeugnis des Hausarztes die richtige Verdachtsdiagnose festgehalten war, gestützt auf charakteristische Anamnese und Befunde. Wir haben gewonnen oder sie haben wieder einmal verloren, meinen auch die akademischen Fussballfreunde je nach Spielresultat der Nationalmannschaft. Ich $\rightarrow$ wir $\rightarrow$ sie $\rightarrow$ man $\rightarrow$ es sind die Stationen der zunehmenden persönlichen Distanzierung vom Geschehen.

Kaum mehr zu hören ist der fürsorgliche Plural, den bemutternde Pflegerinnen bei betagten Patienten benützten: «Wie haben wir geschlafen? Fein, jetzt essen wir noch ein Stück Zwieback. Und dann machen wir Pipi in diese Flasche!» Die moderne Pflegefachfrau «macht» einen Eintrittsurinstatus und lässt den Becher ins Labor bringen ...

\section{Literatur}

1 de Roche R. Zurück ans Krankenbett! Schweiz Med Forum. 2006;6(49):1114. 